\title{
One effect to rule them all? A comment on climate and conflict
}

\author{
H. Buhaug • J. Nordkvelle • T. Bernauer • T. Böhmelt • \\ M. Brzoska • J. W. Busby • A. Ciccone • H. Fjelde • \\ E. Gartzke • N. P. Gleditsch • J. A. Goldstone • H. Hegre • \\ H. Holtermann • V. Koubi • J. S. A. Link • P. M. Link • \\ P. Lujala • J. O'Loughlin • C. Raleigh • J. Scheffran • \\ J. Schilling • T. G. Smith • O. M. Theisen • R. S. J. Tol • \\ H. Urdal • N. von Uexkull
}

Received: 6 December 2013 / Accepted: 28 September 2014 / Published online: 27 October 2014

C) The Author(s) 2014. This article is published with open access at Springerlink.com

\begin{abstract}
A recent Climatic Change review article reports a remarkable convergence of scientific evidence for a link between climatic events and violent intergroup conflict, thus departing markedly from other contemporary assessments of the empirical literature. This commentary revisits the review in order to understand the discrepancy. We believe the origins of the disagreement can be traced back to the review article's underlying quantitative meta-analysis,
\end{abstract}

An author's reply to this comment is available at doi:10.1007/s10584-014-1276-z.

This comment refers to the article available at doi:10.1007/s10584-013-0868-3.

Electronic supplementary material The online version of this article (doi:10.1007/s10584-014-1266-1) contains supplementary material, which is available to authorized users.

H. Buhaug $(\bowtie) \cdot$ J. Nordkvelle $\cdot$ N. P. Gleditsch $\cdot$ H. Hegre $\cdot$ H. Urdal

Peace Research Institute Oslo (PRIO), Oslo, Norway

e-mail: halvard@prio.org

H. Buhaug • N. P. Gleditsch • O. M. Theisen

Department of Sociology and Political Science, Norwegian University of Science and Technology,

Trondheim, Norway

T. Bernauer · T. Böhmelt • V. Koubi

Center for Comparative and International Studies, ETH Zurich, Zurich, Switzerland

T. Böhmelt • E. Gartzke

Department of Government, University of Essex, Colchester, UK

M. Brzoska $\cdot$ J. S. A. Link $\cdot$ P. M. Link $\cdot$ J. Scheffran $\cdot$ J. Schilling

KlimaCampus, University of Hamburg, Hamburg, Germany

J. W. Busby • T. G. Smith

Lyndon B. Johnson School of Public Affairs, University of Texas, Austin, USA

A. Ciccone

Department of Economics, University of Mannheim, Mannheim, Germany 
which suffers from shortcomings with respect to sample selection and analytical coherence. A modified assessment that addresses some of these problems suggests that scientific research on climate and conflict to date has produced mixed and inconclusive results.

Hsiang and Burke (2014) examine 50 quantitative empirical studies and find a "remarkable convergence in findings" (p. 52) and "strong support for a causal association" (p. 42) between climatological changes and conflict at all scales and across all major regions of the world. A companion paper by Hsiang et al. (2013) that attempts to quantify the average effect from these studies indicates that a 1 standard deviation $(\sigma)$ increase in temperature or rainfall anomaly is associated with an $11.1 \%$ change in the risk of "intergroup conflict". 1 Assuming that future societies respond similarly to climate variability as past populations, they warn that increased rates of human conflict might represent a "large and critical impact" of climate change.

What Hsiang and Burke set out to do - to synthesize scientific evidence on climate and conflict - is a timely task, and their study adds to an increasingly long list of scientific reviews

\begin{abstract}
${ }^{1}$ For reasons that are not clear, there is not perfect overlap between Hsiang and Burke's sample of 50 "rigorous quantitative studies" and Hsiang et al.'s 60 "most rigorous quantitative studies", and there are also some inconsistencies in how some studies are categorized. In this comment, we focus only on the subset of studies that concern modern (i.e., post-1950) "intergroup conflict", comprising civil and communal conflict. Twenty of the 21 studies of this kind reviewed by Hsiang and Burke are also part of Hsiang et al.'s meta-analysis.
\end{abstract}

H. Fjelde $\cdot$ H. Hegre $\cdot$ N. von Uexkull

Department of Peace and Conflict Research, Uppsala University, Uppsala, Sweden

E. Gartzke

Department of Political Science, University of California, San Diego, USA

J. A. Goldstone

School of Public Policy, George Mason University, Fairfax, USA

J. A. Goldstone

Research Laboratory on Political Demography, Russian Academy of National Economy and Public

Administration, Moscow, Russia

H. Holtermann

Department of Political Science, University of Oslo, Oslo, Norway

V. Koubi

Department of Economics, University of Bern, Bern, Switzerland

P. Lujala

Department of Geography, Norwegian University of Science and Technology, Trondheim, Norway

J. O'Loughlin

Institute of Behavioral Science, University of Colorado, Boulder, USA

C. Raleigh

Department of Geography, University of Sussex, Brighton, UK

J. Schilling

International Alert, London, UK

R. S. J. Tol

Department of Economics, University of Sussex, Bringhton, UK

R. S. J. Tol

Department of Spatial Economics, Free University Amsterdam, Amsterdam, Netherlands 
published in the recent past (Adger et al. 2014; Bernauer et al. 2012; Gleditsch 2012; Klomp and Bulte 2013; Meierding 2013; Scheffran et al. 2012a,b; Theisen et al. 2013; Zografos et al. 2014). However, Hsiang and Burke depart from these other reviews in two important ways. First, their conclusion about a consistent and robust climate effect contrasts dominant observations, such as "researchers have failed to uncover consistent linkages between environmental shifts and intrastate contention" (Meierding 2013, 185); "we find little robust evidence linking weather shocks to the onset of conflict" (Klomp and Bulte 2013, 63); and, arguably most prominently, the comprehensive Human Security chapter of the UN's Intergovernmental Panel on Climate Change's Fifth Assessment Report: "collectively the research does not conclude that there is a strong positive relationship between warming and armed conflict" (Adger et al. 2014, 16). Second, Hsiang and Burke's review stands out by being founded on an attempt to quantify the "true" climate effect on conflict. This is done through a meta-analysis of replication data from selected statistical articles and unpublished papers on climate and human conflict (Hsiang et al. 2013).

We believe an important reason for the notable discrepancy in views between Hsiang and Burke and the larger scholarly community can be traced back to problems related to the accompanying meta-analysis. ${ }^{2}$ This commentary identifies three limitations with the metaanalysis, and implicitly with Hsiang and Burke's review, and shows that well-justified modifications to the original setup result in a different conclusion. The problems that we consider here relate to three underlying assumptions of the meta-analysis: (1) cross-study independence, (2) causal homogeneity, and (3) sample representativeness. While Hsiang et al. consider these problems at length in the supplementary material, their portrayal of the statistical association and the unambiguous conclusion in both review articles reveal that they do not attribute much weight to these concerns when interpreting the results.

First, the underlying meta-analysis rests on the assumption that sample studies are fully independent, although it is clear that there is considerable overlap between them. Every civil conflict work considered by Hsiang and Burke (2014) and 19 of 22 studies on the modern climate-intergroup conflict inHsiang et al. (2013) include African countries, and more than half of these are limited to post-1980 Sub-Saharan Africa. In one case, the cross-study correlation is estimated at $\mathrm{r}=0.6$ (see supplementary information). Accordingly, the variance-weighted calculation of climate effects conducted by Hsiang et al. returns unrealistically precise estimates and the true uncertainty around the average climate effect is much larger than reported. ${ }^{3}$ Instead of relying on the overly narrow variance-weighted confidence interval, Hsiang and coauthors would have done better (i.e., provided a more conservative test) by referring to the $95 \%$ density interval of the distribution of the effect sizes.

Second, Hsiang and Burke's sample of "intergroup conflict" studies covers a wide range of social phenomena, from non-violent land grabbing via urban riots to major civil war; a wide range of climatic events, from heat waves via excess rainfall to global ENSO cycles; and a wide range of spatial scales, from municipalities via countries to the entire world. Moreover, the surveyed studies differ widely in how the climate effect is theorized and modeled, which sometimes is linear, at other times parabolic; sometimes instant and at other times materialize

\footnotetext{
${ }^{2}$ The noted discrepancy between Hsiang and Burke (and coauthors) and other scholars has triggered several commentaries and responses; see, for example, Buhaug (2014), Hsiang and Meng (2014), Raleigh et al. (2014), and O'Loughlin et al. (2014).

${ }^{3}$ In Hsiang et al.'s supplementary material, cross-study correlation is discussed and alternative and more appropriate estimations of uncertainty are indicated, whereby the $95 \%$ precision interval around the mean effect ranges from -7.8 to 40.1 (Hsiang et al. Table S1; see also right panel of Hsiang et al.'s Fig. 5). Crucially, the interpretation of this interval is different than for the variance-weighted interval, as it is here acknowledged that effects vary between studies (it is possible that climate effects sometimes are positive, and sometimes negative). It is not evident, however, what is gained by quantifying the variation in such a heterogeneous sample over and beyond what thorough qualitative reviews of the quantitative literature can (and do) offer.
} 
after a distinct temporal lag. Claiming the same underlying climate effect across these heterogeneous studies is certainly a bold assumption, but it is essential for the meta-analysis to be meaningful. A careful reading of the literature, or inspection of Fig. 1 below, reveals a variation in findings that is inconsistent with the assumption of causal homogeneity.

Third, aggregating and generalizing results from selected studies serve no larger purpose unless the sample constitutes a representative subset of all relevant scientific research. Yet, the sample inclusion strategy adopted by Hsiang and coauthors favors form over function by using selection criteria that explicitly disregard studies that revisit previously investigated climateconflict associations, regardless of whether they complement, contrast or correct earlier findings. For example, the country-level relationship between rainfall and civil conflict is represented in the meta-analysis by a single peer-reviewed result (Miguel et al. 2004), omitting numerous more recent investigations that reach different conclusions (e.g., Buhaug 2010; Burke et al. 2009; Ciccone 2011; Couttenier and Soubeyran 2013; Koubi et al. 2012). ${ }^{4}$ Moreover, the meta-analysis, and implicitly also the non-technical assessment in Hsiang and Burke, considers just one climate indicator from each study, in many cases the one that indicated the strongest effect, although many of the original studies actually explore multiple alternative and complementary climate measures that sometimes produce contrasting results. ${ }^{5}$ We do not believe that oversampling of significant results is a fruitful way to provide a balanced and sound review of the scientific evidence base for a causal climate-conflict link.

These are not trivial concerns, and they add up. In an effort to address these issues, we replicated Hsiang et al.'s meta-analysis after implementing three changes. More specifically, we first streamlined the sample by limiting the selection of studies to those investigating violent political conflict between organized non-state actors and state military forces (i.e., civil conflicts). This is the form of conflict with the gravest social and political implications, and narrowing the scope of the dependent variable increases the plausibility of the assumed common causal effect. Second, to obtain a more representative sample and to avoid the temptation to selectively pick indicators that produce a desired result, we included all main climate variables investigated in the relevant studies. For the same reason, and to ensure analytical consistency and the correct sequence of events, we also applied a consistent lag of one time period $(\mathrm{t}-1)$ to all climate parameters across all models. ${ }^{6}$

The updated meta-analysis with all three modifications implemented is visualized in Fig. 1. The result is striking. In contrast to Hsiang and coauthors, we find no evidence of a convergence of findings on climate variability and civil conflict. Recent studies disagree not only on the magnitude of the impact of climate variability but also on the direction of the effect. The aggregate median effect from these studies suggests that a one-standard deviation increase in temperature or loss of rainfall is associated with a $3.5 \%$ increase in conflict risk, although the $95 \%$ highest density area of the distribution of effects cannot exclude the

\footnotetext{
${ }^{4}$ Some of the studies that are omitted in Hsiang and colleagues' assessment of the rainfall-conflict link are represented in the meta-analysis with other, typically more significant effects (e.g., temperature or drought).

${ }^{5}$ To give one example, Hsiang and colleagues' review of Couttenier and Soubeyran (2013) is limited to citing and replicating the result for the PDSI index, thus ignoring the study's findings with regard to the other climatological indicators. Couttenier and Soubeyran $(2013,213)$ report that "[t]he effect of $(\log )$ rainfall is still surprisingly positive and the effect of temperature is still positive. Their effects are insignificant and the contemporaneous and lagged measures are jointly insignificant." While we agree that the PDSI finding is important and deserves attention, ignoring results that contrast the general narrative inevitably provides a distorted view.

${ }^{6}$ The surveyed studies are not consistent in their treatment of time, reflecting the lack of a precise and rigorous theoretical model that can be applied across cases, scales, and definitions of conflict. Some studies report contemporaneous effects, others report time-lagged effects, and several studies report both contemporaneous and lagged climate effects.
} 


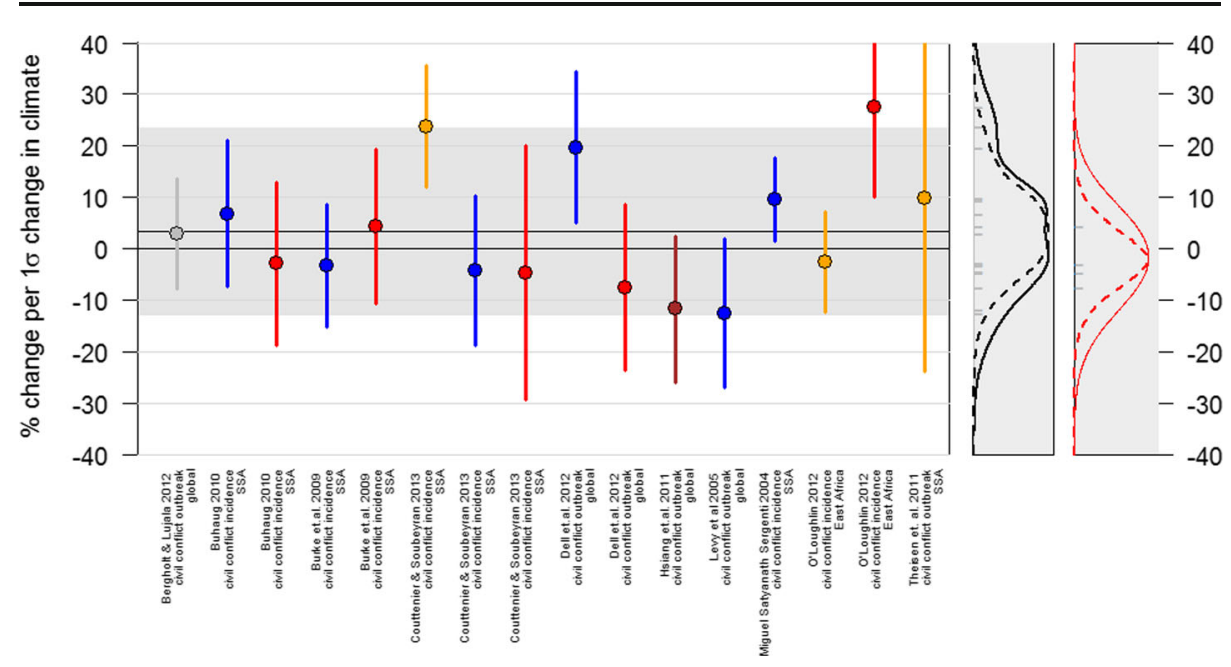

Fig. 1 Modern empirical estimates for the effect of climate variability on civil conflict. The markers illustrate the estimated percentage change in conflict with a $1 \sigma$ increase in temperature (red), loss of rainfall (blue), increase in drought (orange), El Niño-like conditions (brown) or increase in severity of climatic natural disasters (gray). Whiskers denote the $95 \%$ confidence interval. The solid horizontal line indicates the median climate effect with the $95 \%$ highest density interval in grey, based on a Bayesian hierarchical model. The panels at the right show the distribution of results from all candidate studies (black) or those focusing squarely on temperature effects (red); solid lines represent the variance-weighted distribution while dashed lines depict the Bayesian hierarchical distribution. Studies listed alphabetically

possibility of large negative or positive effects. With all contemporaneous effects, the aggregate point estimate increases somewhat but remains statistically indistinguishable from zero.

Does our updated meta-analysis provide the true quantification of the average effect of climate on violent conflict? We dare say no. While the modifications we have implemented increase analytical consistency and representativeness and offer a meaningful alternative specification, a fundamental problem of this analysis remains largely unaddressed. Unlike meta-analyses of medical treatment studies, which are based on similar individual-level investigations from independent sample populations, this assessment bundles together partly overlapping observations at different spatial and temporal scales in an inconsistent and atheoretical fashion. Quantifying the "average" effect across this heterogeneous sample, weighting results by statistical precision but ignoring variations in substantive relevance and potential for generalization, is unlikely to be fruitful, unless there are good theoretical reasons to expect common causal effects. It is a bit like averaging the prices of apples and oranges, sampled in different locations and time periods, at different scales, using different metrics in the absence of a strong basis to expect that they are driven by the same factor(s). The exercise is mathematically feasible but the outcome may have no relevant meaning. Remedying this problem can only be done by taking into account the substantive content of candidate studies, ensuring similar units of analysis across studies based on unique samples, and parameterizing empirical indicators in a theoretically consistent manner. ${ }^{7}$

\footnotetext{
${ }^{7}$ In other words, to facilitate a meta-analysis of this kind, one should focus on one specific form of outcome (e.g., fatal rebel-military conflict events), one specific form of treatment (e.g., high temperature anomaly), one common spatiotemporal scale (e.g., grid cells with monthly resolution), sampled in unique, non-overlapping locations, and use the exact same parameterization and model specification across datasets. Alternatively, one could conduct a meta-regression analysis to examine the impact of differences among studies on effect sizes.
} 
To be clear, this commentary should not be taken to imply that climate has no influence on armed conflict. Rather, we argue - in line with recent scientific reviews (Adger et al. 2014; Bernauer et al. 2012; Gleditsch 2012; Klomp and Bulte 2013; Meierding 2013; Scheffran et al. 2012a,b; Theisen et al. 2013; Zografos et al. 2014) - that research to date has failed to converge on a specific and direct association between climate and violent conflict. In order to uncover more subtle and complex conditions under which climatic events plausibly may have a measurable impact on conflict dynamics, future research should continue the recent trend toward spatial and temporal disaggregation, focus on political violence beyond civil war, and investigate possible indirect mechanisms and intervening factors (for inspiration, see Fjelde and von Uexkull 2012; O'Loughlin et al. 2012; Theisen 2012; Wischnath and Buhaug 2014).

Acknowledgements This work has been supported in part by the Research Council of Norway, grant 217995/ V10, and the U.S. Army Research Laboratory and the U.S. Army Research Office via the Minerva Initiative, grant W911NF-13-1-0307.

Open Access This article is distributed under the terms of the Creative Commons Attribution License which permits any use, distribution, and reproduction in any medium, provided the original author(s) and the source are credited.

\section{References}

Adger, N. et al. (2014) Chapter 12: Human security. In Climate Change 2014: Impacts, Adaptation, and Vulnerability, Working group II contribution to the IPCC fifth assessment report

Bernauer T, Böhmelt T, Koubi V (2012) Environmental changes and violent conflict. Environ Res Lett 7:015601. doi: $10.1088 / 1748-9326 / 7 / 1 / 015601$

Buhaug H (2010) Climate not to blame for African civil wars. Proc Natl Acad Sci U S A 107:16477-16482. doi: $10.1073 /$ pnas. 1005739107

Buhaug H (2014) Concealing agreements over climate-conflict results. Proc Natl Acad Sci U S A 111:E636. doi: $10.1073 /$ pnas. 1323773111

Burke M, Miguel E, Satyanath S, Dykema J, Lobell D (2009) Warming increases risk of civil war in Africa. Proc Natl Acad Sci U S A 106:20670-20674. doi:10.1073/pnas.0907998106

Ciccone A (2011) Economic shocks and civil conflict: a comment. Am Econ J Appl Econ 3:215-227. doi:10. 1257/app.3.4.215

Couttenier M, Soubeyran R (2013) Drought and civil war in Sub-Saharan Africa. Econ J. doi:10.1111/ecoj.12042

Fjelde H, von Uexkull N (2012) Climate triggers: rainfall anomalies, vulnerability and communal conflict in subSaharan Africa. Polit Geogr 31:444 453. doi:10.1016/j.polgeo.2012.08.004

Gleditsch NP (2012) Whither the weather? Climate change and conflict J Peace Res 49:3-9. doi:10.1177/ 0022343311431288

Hsiang SM, Burke M (2014) Climate, conflict, and social stability: what does the evidence say? Clim Change 123:39-55. doi:10.1007/s10584-013-0868-3

Hsiang, S.M., Burke, M., Miguel, E. (2013) Quantifying the influence of climate on human conflict. Science 341. doi: $10.1126 /$ science. 1235367

Hsiang SM, Meng K (2014) Reconciling disagreement over climate-conflict results in Africa. Proc, Natl. Acad. Sci. U.S.A. doi:10.1073/pnas.1316006111, 111

Klomp J, Bulte E (2013) Climate change, weather shocks, and violent conflict: a critical look at the evidence. Agric Econ 44:63-78. doi:10.1111/agec.12051

Koubi V, Bernauer T, Kalbhenn A, Spilker G (2012) Climate variability, economic growth, and civil conflict. J Peace Res 49:113-127. doi:10.1177/0022343311427173

Meierding E (2013) Climate change and conflict: avoiding small talk about the weather. Int Stud Rev 15:185203. doi:10.1111/misr. 12030

Miguel E, Satyanath S, Sergenti E (2004) Economic shocks and civil conflict: an instrumental variables approach. J Polit Econ 112:725-753. doi:10.1086/421174 
O'Loughlin J, Witmer FD, Linke AM, Laing A, Gettelman A, Dudhia J (2012) Climate variability and conflict risk in East Africa, 1990-2009. Proc Natl Acad Sci U S A 109:18344-18349. doi:10.1073/pnas.1205130109

O'Loughlin J, Linke AM, Witmer FD (2014) Modeling and data choices sway conclusions about climate-conflict links. Proc, Natl. Acad. Sci. U.S.A. doi:10.1073/pnas.1323417111, 111

Raleigh C, Linke A, O'Loughlin J (2014) Extreme temperatures and violence. Nature Clim Change 4:76-77. doi: 10.1038/nclimate2101

Scheffran J, Brzoska M, Kominek J, Link PM, Schilling J (2012a) Climate change and violent conflict. Science 336:869-871. doi:10.1126/science.1221339

Scheffran J, Brzoska M, Kominek J, Link PM, Schilling J (2012b) Disentangling the climate-conflict nexus: empirical and theoretical assessment of vulnerabilities and pathways. Rev Eur Stud 4:1-13. doi:10. 5539/res.v4n5p1

Theisen OM (2012) Climate clashes? Weather variability, land pressure, and organized violence in Kenya, 19892004. J Peace Res 49:81-96. doi:10.1177/0022343311425842

Theisen OM, Gleditsch NP, Buhaug H (2013) Is climate change a driver of armed conflict? Clim. Change 117: 613-625. doi:10.1007/s10584-012-0649-4

Wischnath G, Buhaug H (2014) On Climate Variability and Civil War in Asia. Clim Change 122:709-721. doi: 10.1007/s10584-013-1004-0

Zografos C, Goulden MC, Kallis G (2014) Sources of human insecurity in the face of hydro-climatic change. Glob Env Change. doi:10.1016/j.gloenvcha.2013.11.002 